ISSN: 2637-4676

\title{
Mississippi State Preparing Leaders in Unmanned Aerial Systems
}

\author{
Vanessa Beeson, Karen Brasher and Amelia Fox* \\ https://www.futuregrowers.cals.msstate.edu/ \\ *Corresponding author: Amelia Fox, Asst. Clinical Professor and Future Grower Technologies Project Manager, Mississippi State \\ University Plant and Soil Sciences, USA
}

\section{Opinion}

The 2019 Federal Aviation Administration (FAA) Aerospace Forecast expects the number of small unmanned aircraft systems (sUAS) or drones registered for commercial use and the number of remote pilots certified to fly them to triple in the next five years. At the current rate of growth, the FAA expects the sUAS-certified remote pilots to outnumber pilots of manned aircraft by 2023, if not sooner. Currently, there are more than 428,000 commercial drones registered and over 162,000 remote pilots certified to fly for commercial purposes [1-3].

As both the commercial use of sUAS and the need for remote pilots increase exponentially, Mississippi State University has risen to fill the gap. MSU's extensive work in remote sensing technologies provides students with opportunities to become leaders in this emerging field. MSU is quickly becoming a national authority in this arena as the lead university for the FAA Alliance for System Safety of UAS through Research Excellence (ASSURE). The university also leads the U.S. Department of Homeland Security Common UAS Test
Site and is building an advanced wireless testbed as part of the Aerial Experimentation Research Platform for Advanced Wireless, or AERPAW, a National Science Foundation and industry-sponsored project focused on integrating unmanned aerial vehicles, or drones, into $5 \mathrm{G}$ networks to increase connectivity.

Two Mississippi State courses in small Unmanned Aerial Systems technology are preparing a new generation of drone pilots. As a hub for precision agriculture training, MSU is offering the new courses in the College of Agriculture and Life Sciences to help pilots pass the certification required by the FAA to fly UAS commercially. Amelia Fox, assistant clinical professor in the Department of Plant and Soil Sciences, teaches two split-level courses in ag flight technologies-Ag Flight Technologies I and Ag Flight Technologies Figure 1 II. While the courses are centered on promoting wouldbe pilots to pass the FAA Remote Pilot certificate exam, students receive hands-on flight instruction through the Academy of Model Aeronautics training protocol, achieving certification in both fixedwing and roto-copter technology (Figures 1,2).

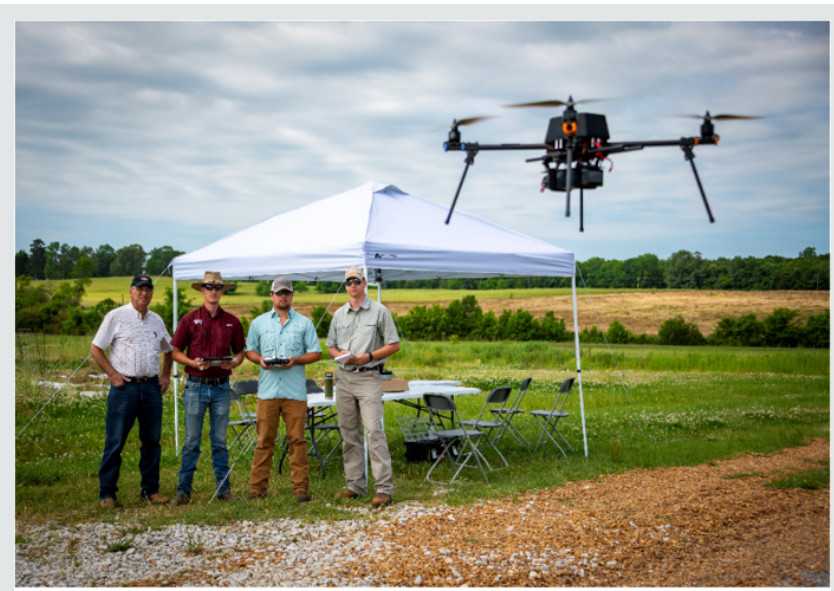

Figure 1: Dennis Lott, Graham Oakley, Addison Meeks and Lucas Whittenton take turns practicing flying during an Ag Flight Technologies Class at Mississippi State University on Tuesday, May 14, 2019. 


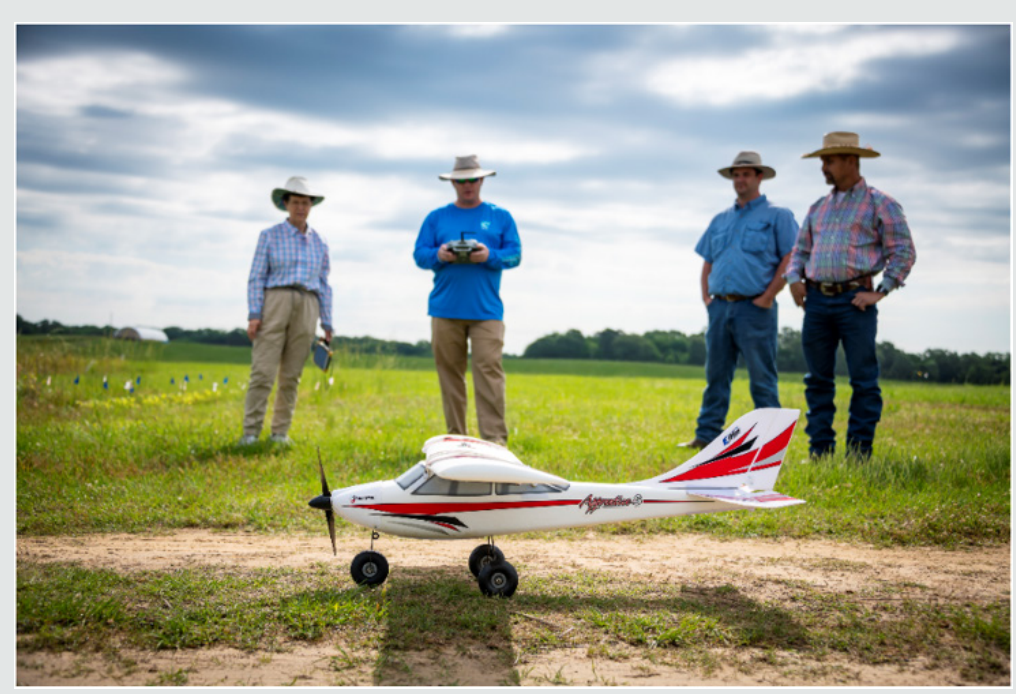

Figure 2: Amelia Fox, Beau Varner and Rocky Lemus look on as Michael Natrass (center left) operates a fixed-wing UAV.

The courses are part of a growing number of precision ag offerings available at MSU. Students also may enroll in Fox's Ag Remote Sensing courses to learn how to manage and present data collected from unmanned aircraft. Fox said basic and advanced ag flight technologies fill a significant gap in UAS flight training. "In the U.S. we can't meet the workforce demand for pilots. Of the 150 aeronautical post-secondary schools in the U.S. today, each would have to graduate about 500 FAA-certified pilots a year to meet the workforce demand by 2022. These courses are meant to help with that issue," Fox said. She said the classes are focused on getting pilots ready to move into immediate employment positions. The courses are open to all MSU students and Fox said she is particularly targeting those interested in graduate school.
"We want to find capable students who can serve their directors in research, continue on to grad school, and fly in other capacities for the university," Fox said. Dennis Lott of Clinton, MS-based UAS Solutions, LLC, contracts with MSU to conduct advanced training to students entering the workforce and to further novel research in agriculture. Lott fabricates advanced flight systems for the program and collaborates on research that evaluates benefits of fixed-wing flight systems as a potential replacement to the slower, roto-copter systems. In addition to learning material presented on the FAA Remote Pilot Certification exam and both students are gaining an understanding on how to assess crop status and agricultural input needs based on aerial imagery obtained through sUAS (Figure 3).

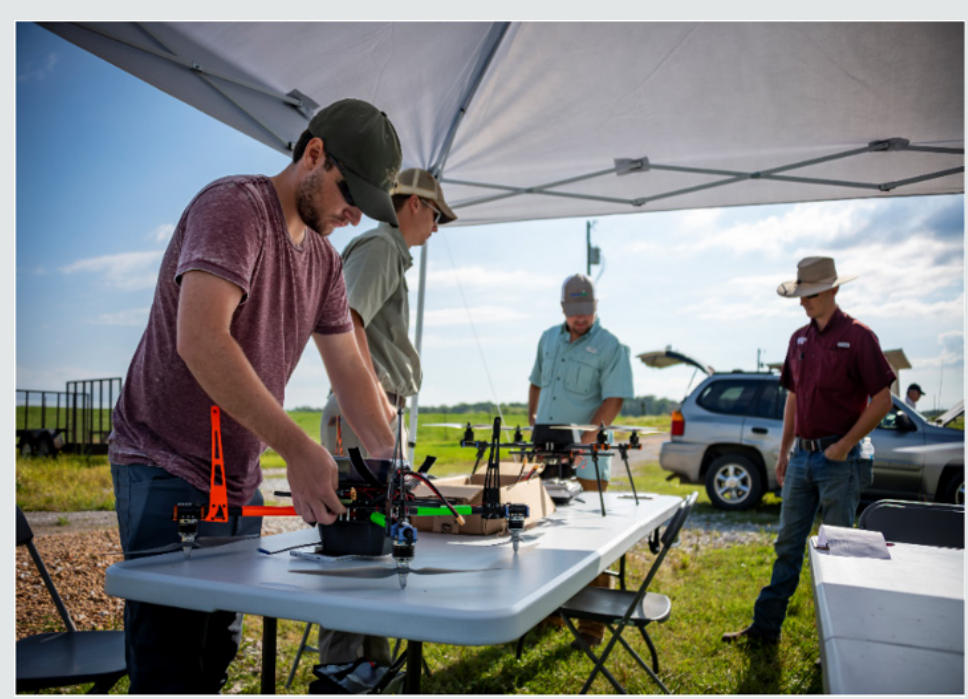

Figure 3: Jonathan Braud, Lucas Whittenton, Addison Meeks and Graham Oakley examine drones before flight.

The primary focus of this research is improving nitrogen use efficiency through early crop sensing. Unmanned flight systems are flown over young crops and nitrogen demand is estimated using multispectral sensors. Variable-rate nitrogen prescription maps are created to aid producers in applying optimal, and often reduced, amounts of fertilizer while maintaining desirable yields. Training materials for computer-aided farm production courses have been developed by Fox, including the Precision Agriculture 
GIS Technologies for Mississippi curriculum and accompanying dataset, available for download at https://irlibrary.msstate.edu/ handle/11668/14835. Fox has authored five different GIS and remote sensing textbooks aimed at advancing student engagement in computer-based farm technologies. Fox is also the primary investigator under a $\$ 500,000$ federal grant to produce virtual reality training software that teaches high-tech operators how to navigate environmentally controlled farm production systems. The U.S. Department of Agriculture award is funding a crosscollaborative project between MSU's College of Agriculture and Life Sciences and James Worth Bagley College of Engineering that is building virtual reality technology for training students to work in state-of-the-art facilities such as greenhouses and similar buildings used for poultry, swine, and grain feed mills.

As an instructional faculty member, Fox has found pleasure in chasing novel research avenues by partnering with industry leaders. Keeping the primary focus on student advancement, her future coursework with Lott includes a flight systems fabrication course where students purchase off-the-shelf equipment and build a commercial-class copter capable of carrying a one-pound sensor. Graduate students engage in cotton, corn, and peanut research through these technologies and the program hopes to expand to forage sensing within a year. Fox and Lott collaborate with other MSU research faculty including: Jac Varco, nitrogen sensing specialist; Brendan Zurweller, peanut specialist; Rocky Lemus, forage specialist and https://www.futuregrowers.cals.msstate. edu/.

Trained students will fill a critical need in this emerging field. According to the Association for Unmanned Vehicle Systems International, the domestic sUAS market is projected to create more than 100,000 jobs and $\$ 82$ billion in economic impact in the first decade after FAA integration is complete. During the same period, the sUAS industry could create more than 1,200 jobs and approximately $\$ 973$ million in economic impact in Mississippi alone (Figure 4).

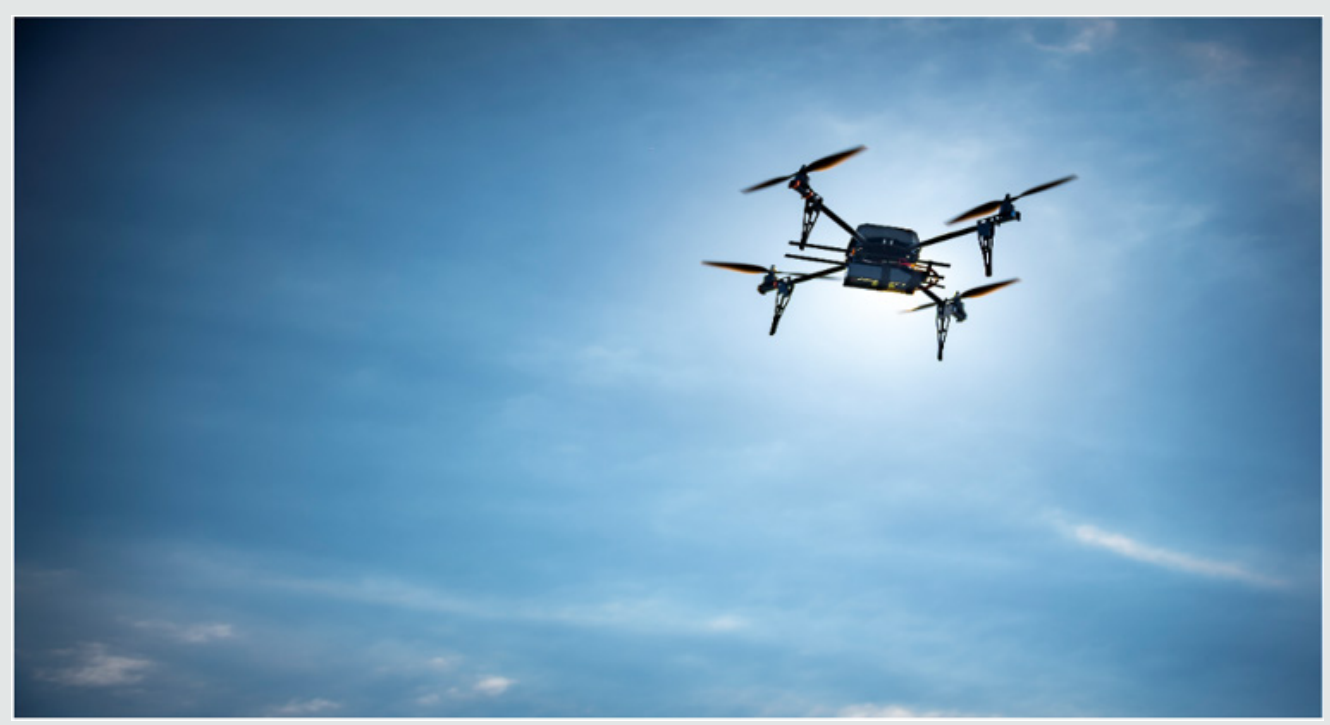

Figure 4: Fox's 650 Class Quad Copter is nicknamed Surely. Surely carries two sensors: a) Goodness, a MicaSense RedEdge ${ }^{\circledR}$ multispectral sensor and b) Mercy, a Canon SX 260 RGB camera.

Photos by David Ammon, MSU Ag and Natural Resources Marketing

Find more information about the College of Agriculture and Life Sciences at https://www.cals.msstate.edu.

An MSU Foundation account has been established to support unmanned flight training. For more information, contact Jud Skelton at jskelton@foundation.msstate.edu or 662-325-0643. MSU is Mississippi's leading university, available online at www. msstate.edu.

\section{References}

1. https://www.faa.gov/news/updates/?newsId=93646

2. https://www.faa.gov/uas/resources/by_the_numbers/

3. https://www.aopa.org/news-and-media/all-news/2019/may/07/faaforecast 
(c) (i) This work is licensed under Creative Commons Attribution 4.0 License To Submit Your Article Click Here: Submit Article

DOI: $10.32474 /$ CIACR.2020.08.000281

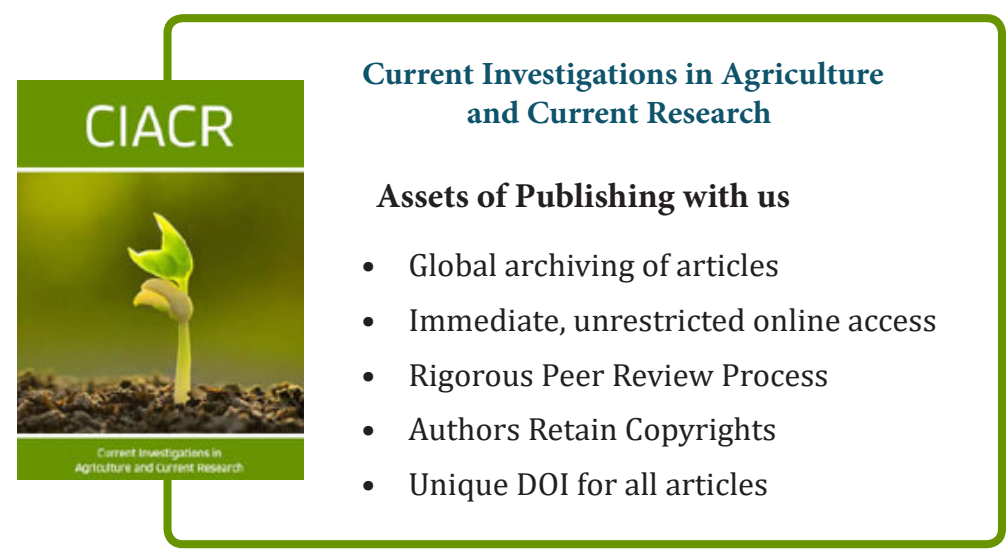

